\title{
BMJ Open Funding allocation to surgery in low and middle-income countries: a retrospective analysis of contributions from the USA
}

\author{
Lily Gutnik, ${ }^{1,2,3}$ Joseph Dieleman, ${ }^{4}$ Anna J Dare, ${ }^{5}$ Margarita S Ramos, ${ }^{2}$ \\ Robert Riviello, ${ }^{2,6}$ John G Meara, ${ }^{6,7}$ Gavin Yamey, ${ }^{8}$ Mark G Shrime ${ }^{9,10}$
}

To cite: Gutnik L,

Dieleman J, Dare AJ, et al. Funding allocation to surgery in low and middle-income countries: a retrospective analysis of contributions from the USA. BMJ Open 2015;5:e008780. doi:10.1136/bmjopen-2015008780

- Prepublication history for this paper is available online. To view these files please visit the journal online (http://dx.doi.org/10.1136/ bmjopen-2015-008780)

Received 15 May 2015 Revised 7 October 2015 Accepted 13 October 2015

CrossMark

For numbered affiliations see end of article.

Correspondence to

Dr Lily Gutnik;

Lily.gutnik@mail.harvard.edu

\section{ABSTRACT}

Objective: The funds available for global surgical delivery, capacity building and research are unknown and presumed to be low. Meanwhile, conditions amenable to surgery are estimated to account for nearly $30 \%$ of the global burden of disease. We describe funds given to these efforts from the USA, the world's largest donor nation.

Design: Retrospective database review. US Agency for International Development (USAID), National Institute of Health $(\mathrm{NIH})$, Foundation Center and registered US charitable organisations were searched for financial data on any organisation giving exclusively to surgical care in low and middle income countries (LMICs). For USAID, NIH and Foundation Center all available data for all years were included. The five recent years of financial data per charitable organisation were included. All nominal dollars were adjusted for inflation by converting to 2014 US dollars.

Setting: USA.

Participants: USAID, NIH, Foundation Center, Charitable Organisations.

Primary and secondary outcome measures: Cumulative funds appropriated to global surgery.

Results: $22 \mathrm{NIH}$ funded projects (totalling $\$ 31.3$ million) were identified, primarily related to injury and trauma. Six relevant USAID projects were identifiedall obstetric fistula care totalling $\$ 438$ million. A total of $\$ 105$ million was given to universities and charitable organisations by US foundations for 12 different surgical specialties. 95 US charitable organisations representing 14 specialties totalled revenue of $\$ 2.67$ billion and expenditure of $\$ 2.5$ billion.

Conclusions and relevance: Current funding flows to surgical care in LMICs are poorly understood. US funding predominantly comes from private charitable organisations, is often narrowly focused and does not always reflect local needs or support capacity building. Improving surgical care, and embedding it within national health systems in LMICs, will likely require greater financial investment. Tracking funds targeting surgery helps to quantify and clarify current investments and funding gaps, ensures resources materialise from promises and promotes transparency within global health financing.

\section{Strengths and limitations of this study}

- This was the first known attempt to track and quantify funds appropriated to surgical care in low and middle income countries.

- Lack of streamline accounting processes and classification terms make it challenging to identify funds towards global surgery.

- There are inherent limitations in keyword searches of large databases, perhaps missing data points.

\section{INTRODUCTION}

Surgical care is an important component of a functioning health system for all countries. Conditions requiring surgical care-including maternal and neonatal conditions, digestive diseases, cancers, congenital abnormalities and injuries-account for 11-30\% of the global burden of disease. ${ }^{1-3}$ Much of the morbidity and mortality from surgical conditions in low and middle income countries (LMICs) could be averted through improved access to surgery. ${ }^{4}$ About 5 billion people lack access to safe, affordable, timely surgical care; and, in LMIC this problem is magnified where nine out of 10 people cannot access basic surgical care. ${ }^{5}$ Yet surgery has remained a low priority on the global health agenda as well as the national health agenda in most LMICs. For example, a systematic review of National Health Strategic Plans in 43 African countries found that $19 \%$ had no mention of surgery and $65 \%$ mentioned it five or fewer times. ${ }^{6}$ As a result, population access to surgical care is poor and surgical systems in LMICs remain severely under-resourced. ${ }^{7-10}$ This neglect of surgery is despite evidence of its cost-effectiveness in low resource settings. ${ }^{11} 12$ To improve surgical care and outcomes in the world's poorest regions, greater financial investment is likely required. 
However, little is known about current financing flows to surgery in LMICs, making it difficult to quantify funding shortfalls, or to determine how donors may be influencing the availability and distribution of surgical services.

Over the past 15 years, financial aid for global health has been on the rise. ${ }^{13-17}$ In 2013, $\$ 31.3$ billion was provided to development assistance for health (DAH). ${ }^{13}$ The amount of DAH targeted to surgical care is unclear, because DAH databases do not specifically collect data on surgical services and many funders only report investments using broad, aggregated classifications.

The USA is among the top five leading donors to global health. ${ }^{17}$ In 2012, USAID (the US Agency for International Development) spent $\$ 5.5$ billion on health, ranking it the highest funded programme area. ${ }^{18}$ In addition to funding directed through international development agencies, the US also funds biomedical research and training in global health. For example, the National Institutes of Health (NIH), the US federal agency of biomedical and health research, operated a budget of almost $\$ 30$ billion in 2013, nearly the global aggregated sum of DAH in 2013. ${ }^{13}{ }^{19}$ However, in the same year, the Fogarty International Center, the NIH's global health institute, received only $\$ 65.7$ million of that $\$ 30$ billion budget $(0.22 \%) .{ }^{19}$ Given the sheer scale of US global health funding, understanding US-derived funding flows to surgery in LMICs can offer important insights into how DAH targets surgical care. We conducted a retrospective database review in an attempt to estimate how much DAH flows from the US to surgical services in LMICs.

\section{METHODS}

We identified four major funding channels from which we can estimate resources allocated to surgical efforts in low resource settings. These include US charitable organisations, foundations, USAID and the NIH.

\section{Charitable organisations}

We defined charitable organisations as non-profit, nongovernmental organisations that serve the public interest. The included organisations represent the spectrum of platforms for surgery described by Shrime $e t$ al $l^{1}$ shortterm trips, specialised hospitals and self-contained platforms. The non-profit and volunteer sector, which charitable organisations fall under, is a significant economic sector; its growth has outpaced gross domestic product growth by $20 \% .{ }^{20}$ In 2013 alone, charitable organisations accounted for $15.7 \%$ of overall donations to DAH. ${ }^{13}$ Such organisations provide as much as $55 \%$ of surgical care in some LMICs. ${ }^{21}$ In this study we included charitable organisations that provide exclusively surgical care and no other services in LMICs. Organisations providing surgical care in addition to other services were excluded. Although these organisations may receive their funding from a variety of sources including private donations, grants, government contracts and user fees, we are only able to track aggregated funds that are reported on federal tax form 990 (our data source).

Charitable organisations that provide exclusively surgical care were identified from the surgical volunteerism listings on numerous websites (table 1). Next, each listed organisation website was reviewed to ensure adherence to inclusion criteria of providing exclusively surgical care in LMICs. Tax records (Form 990) provide information on the organisation's revenue and expenses and were retrieved either from the organisation website or from electronic sources listed in table 1.

\section{US foundations}

Health is the single largest focus issue of US foundations, who provide billions of dollars annually in philanthropy. ${ }^{22} \mathrm{~A}$ foundation is 'a non-governmental entity that is established as a non-profit corporation or a charitable trust, with a principal purpose of making grants to unrelated organisations, institutions or individuals for scientific, educational, cultural, religious or other charitable purposes'. ${ }^{23}$ Foundations are different from the charitable organisations described above in that the latter are both funding channels and implementation agents. In contrast, foundations are simply the grantmakers; they do not implement a service. Foundations are further classified as independent, operating, community, corporate, as defined in table 2. The Foundation Center Online Directory (FCOD) is a comprehensive digital library that archives grants made and received by foundations and non-profit organisations. The professional FCOD subscription was used, which has over three million grants covering the past 10 years of their database.

\section{U.S government agencies}

USAID's investment in global health is consistently ranked a top agency funding priority. ${ }^{24}$ The NIH is the world's largest supporter of biomedical research. In fact, one of the 27 institutes is the Fogarty International Center, which is dedicated to training scientists and enhancing research in LMICs. Together, these two agencies are the biggest US government investors in global health. Both USAID and the NIH have online searchable databases chronicling their funded projects, including financial allotment. The NIH has project data from 1990. USAID's project database begins in 1992.

\section{Research methods}

We constructed a separate database for each funding channel. USAID and NIH databases provided project-level information on actual disbursed funds. For foundations, grant details including amount, grant recipient and specified use of funds were extracted. The grants were categorised for surgical specialty supported and the specified purpose of the funds (eg, earmarked dollars). We extracted data on total revenue and the breakdown of total expenditure from the Forms 990. Owing to data limitations, the most current 5 years of 
Table 1 Summary of data source and research methods

\begin{tabular}{ll}
$\begin{array}{l}\text { Funding } \\
\text { channel }\end{array}$ & Definition \\
\hline Foundations & $\begin{array}{l}\text { Non-governmental entity that is } \\
\text { established as a non-profit corporation or } \\
\text { a charitable trust, with a principal purpose } \\
\text { of making grants to unrelated } \\
\text { organisations, institutions or individuals for } \\
\text { scientific, educational, cultural, religious or } \\
\text { other charitable purpose }\end{array}$
\end{tabular}

\section{Data source}

Foundation Center Online Directory

other charitable purpose

Charitable

Non-profit, non-governmental

organisations organisations that serve public interest; many of which qualify for tax credits.

These organisations may receive their

funding from a variety of sources including private donations, grants, government contracts and user fees

USAID

US Agency for International Development, US government agency focusing on

foreign assistance to developing countries

$\mathrm{NIH} \quad$ National Institutes of Health: US medical

research agency from the department of

health and human services
Organisation Identification: American College of Surgeons Operation Giving Back, the Society of Pediatric Anesthesiologists, OmniMed,

Foundation Center Online Directory, US. State

Department Private Volunteer Organizations registry

Form 990: Guidestar, ProPublica, Economics

Research Institute, Citizenaudit.org, National

Center for Charitable Statistics at the Urban

Institute and the Foundation Center Online

Directory

USAID website interactive project mapper

NIH online RePORTER
Methods to identify funds towards global surgery

All database keyword search combinations of the following words: key word searches with combinations of 'global,' 'international,' 'low resource,' 'developing countries/nations' 'research' and 'surgery', 'obstetrics and gynecology,'

'obstetric fistula,' 'trauma,' 'injury,' 'congenital birth defects,' 'cleft lip/palate,' 'cataract,', 'ophthalmology,' 'burn,' 'reconstructive,' 'urology,' 'orthopedics,' 'club foot,' 'neurosurgery,' 'hydrocephalus,' 'anesthesia, ' 'cardiac,' and 'ENT'; manual review of results to assure it was solely related to surgical capacity building, delivery, research and training

Verification of meeting definition criteria by checking each organisation website that was listed on the data source websites.

Manual review of each of the 524 projects listed on the online global health interactive project mapper

Selection of all fiscal years, selection of all LMICs from drop down menu, following keyword searches for all projects descriptions search box: 'surgery', 'obstetrics and gynecology,' 'obstetric fistula,' 'trauma,' 'injury,' 'congenital birth defects,' 'cleft lip/palate,' 'cataract, 'ophthalmology,' 'burn,' 'reconstructive, ' 'urology,' 'orthopedics,' 'club foot,' 'neurosurgery,' 'hydrocephalus,' 'anesthesia,' 'cardiac,' and 'ENT'; manual review of allproject to assure it was solely related to surgical capacity building, delivery, research, and training 
Table 2 Classification of foundations

\begin{tabular}{|c|c|c|}
\hline Type of foundation & Description & Example \\
\hline $\begin{array}{l}\text { Independent } \\
\text { foundation }\end{array}$ & $\begin{array}{l}\text { General category that usually includes } \\
\text { foundations established by individuals and } \\
\text { families }\end{array}$ & Bill and Melinda Gates Foundation \\
\hline Operating foundation & $\begin{array}{l}\text { Foundations that are able to make grants and } \\
\text { financial contributions to other non-profit } \\
\text { organisations but primarily run their own } \\
\text { programme }\end{array}$ & $\begin{array}{l}\text { Lavelle Fund for the Blind is a non-profit } \\
\text { organisation that provides a broad range of } \\
\text { services for people who are blind. This } \\
\text { organisation also has donated funds to other } \\
\text { organisations that work with this same population. }\end{array}$ \\
\hline Community foundation & $\begin{array}{l}\text { Foundations organised by public communities } \\
\text { that raise money from the general public }\end{array}$ & The San Diego Foundation \\
\hline Corporate foundation & $\begin{array}{l}\text { Foundations established by businesses but are } \\
\text { legally separate entities from the main business }\end{array}$ & Bank of America Foundation \\
\hline
\end{tabular}

tax forms were collected for each organisation. The charitable organisations were categorised by type of surgical service they provide. All nominal dollars were adjusted for inflation by converting to 2014 U.S. dollars using the IMF World Economic Outlook database (downloaded in April 2014). Table 1 summarises the data sources and detailed research methods.

\section{RESULTS}

\section{U.S charitable organisations}

Tables 3 and 4 describe the total revenue and expenditure for 95 US charitable organisations providing exclusively surgical care over the years 2007-2013, expressed in 2014 US dollars. The total revenue was $\$ 2.14$ billion, while total expenditure was US $\$ 2.53$ billion 2014. Total programme expenditures were US $\$ 2.14$ billion 2014 while total management costs were $\$ 88.72$ million. Notably, the data are skewed towards the years 2008-2012 due to limited data availability. Similarly, not all tax forms required itemised management expenses, so the $\$ 88$ million figure is a lower bound. The service expense/ total expense measure is the proportion of funds spent on programme services. The median range is 0.71 to 1 . On an average aggregated level these organisations spend anywhere from $71 \%$ to $100 \%$ of their funding on executing their programmes. Ophthalmology and cleft lip/palate care were the top two most funded specialties accounting for more than $75 \%$ of the total revenue while only accounting for $20 \%$ of the total organisations. Overall, $84 \%$ of the total expenses were on programme services costs and the remaining $16 \%$ on other costs such as management, administration and fundraising.

\section{U.S foundations}

The FCOD search yielded 1250 grants awarded to 82 different organisations (2 universities and 80 charitable organisations) between 2003-2013. These grants were made by 470 foundations and totalled $\$ 105.7$ million

Table 3 Summary of total revenue and expenditure for 95 US Charitable organisations committed exclusively to surgical care in LMIC over 2007-2013 in 2014 US dollars

\begin{tabular}{|c|c|c|c|c|c|}
\hline Type of surgery & $\begin{array}{l}\text { Number of } \\
\text { organisations }\end{array}$ & Total revenue (Sum) & $\begin{array}{l}\text { Percentage } \\
\text { of total }\end{array}$ & $\begin{array}{l}\text { Total expenses } \\
\text { (Sum) }\end{array}$ & $\begin{array}{l}\text { Percentage } \\
\text { of total }\end{array}$ \\
\hline Ophthalmology & 11 & $\$ 1256253010.50$ & 47.21 & $\$ 1217295102.00$ & 48.54 \\
\hline Cleft lip/palate & 8 & $\$ 819720317.98$ & 30.39 & $\$ 717832939.70$ & 28.25 \\
\hline Mix & 14 & $\$ 283748366.10$ & 10.63 & $\$ 303464510.20$ & 12.03 \\
\hline Orthopedics & 14 & $\$ 85964691.80$ & 3.24 & $\$ 80620765.84$ & 2.69 \\
\hline Cardiac & 15 & $\$ 75604257.66$ & 2.84 & $\$ 71826159.55$ & 2.86 \\
\hline Paediatric & 8 & $\$ 54621294.05$ & 2.05 & $\$ 48121042.56$ & 1.99 \\
\hline Reconstructive & 10 & $\$ 48305681.69$ & 1.80 & $\$ 50260266.41$ & 1.92 \\
\hline Obstetric fistula & 8 & $\$ 24651950.52$ & 0.93 & $\$ 23198973.80$ & 0.93 \\
\hline Neurosurgery & 2 & $\$ 11915392.06$ & 0.45 & $\$ 10601253.93$ & 0.42 \\
\hline Urology & 1 & $\$ 4893374.11$ & 0.19 & $\$ 4191093.97$ & 0.17 \\
\hline ENT & 1 & $\$ 3493169.92$ & 0.13 & $\$ 566978.10$ & 0.02 \\
\hline Craniofacial & 1 & $\$ 3121609.25$ & 0.12 & $\$ 3844568.83$ & 0.15 \\
\hline Burn & 1 & $\$ 423291.11$ & 0.02 & $\$ 348710.23$ & 0.01 \\
\hline General & 1 & $\$ 283546.77$ & 0.01 & $\$ 236555.18$ & 0.01 \\
\hline All & 95 & $\$ 2672999953.50$ & 100.00 & $\$ 2532408921.00$ & 100.00 \\
\hline
\end{tabular}


Table 4 Breakdown of expenditure for 95 US Charitable organizations committed exclusively to surgical care in LMIC over 2007-2013 in 2014 US dollars

\begin{tabular}{|c|c|c|c|c|c|}
\hline Type of surgery & $\begin{array}{l}\text { Total programme service } \\
\text { expenses (Sum) }\end{array}$ & $\begin{array}{l}\text { Percentage } \\
\text { of total }\end{array}$ & $\begin{array}{l}\text { Total management } \\
\text { expenses (Sum) }\end{array}$ & $\begin{array}{l}\text { Percentage } \\
\text { of total }\end{array}$ & $\begin{array}{l}\text { Service expense/total } \\
\text { expense (Median) }\end{array}$ \\
\hline Ophthalmology & $\$ 1146905574.00$ & 54.30 & $\$ 25232021.67$ & 27.72 & 0.903736607 \\
\hline Cleft Lip/palate & $\$ 501356549.10$ & 23.40 & $\$ 27124232.84$ & 29.91 & 0.781596521 \\
\hline Mix & $\$ 253328682.50$ & 11.93 & $\$ 18558637.91$ & 20.37 & 0.890432927 \\
\hline Orthopedics & $\$ 74106734.52$ & 2.65 & $\$ 2988617.99$ & 5.66 & 0.851596868 \\
\hline Cardiac & $\$ 59824911.09$ & 2.83 & $\$ 5198179.02$ & 5.74 & 0.857549949 \\
\hline Paediatric & $\$ 38866267.74$ & 1.84 & $\$ 1852283.99$ & 4.87 & 0.837718153 \\
\hline Reconstructive & $\$ 39263691.25$ & 1.84 & $\$ 4459333.64$ & 2.05 & 0.781690431 \\
\hline Obstetric fistula & $\$ 18275700.71$ & 0.87 & $\$ 1935357.54$ & 2.14 & 0.817607482 \\
\hline Neurosurgery & $\$ 116048.07$ & 0.01 & $\$ 11283.36$ & 0.01 & 0.884690813 \\
\hline Urology & $\$ 2944251.58$ & 0.14 & $\$ 843406.30$ & 0.94 & 0.715213402 \\
\hline ENT & $\$ 460631.72$ & 0.02 & $\$ 106003.33$ & 0.12 & 0.996284445 \\
\hline Craniofacial & $\$ 3361305.62$ & 0.16 & $\$ 384823.62$ & 0.42 & 0.871443206 \\
\hline Burn & $\$ 279259.59$ & 0.01 & $\$ 22984.77$ & 0.03 & 0.967953626 \\
\hline General & $\$ 236554.13$ & 0.01 & $\$ 0.00$ & 0.03 & 1 \\
\hline All & $\$ 2139326162.00$ & 100.00 & $\$ 88717165.99$ & 100.00 & \\
\hline
\end{tabular}

ENT, ear, nose and throat; LMIC, low and middle income countries.

Reconstructive surgery, cleft surgery and obstetric fistula repair were the specialties that received support from all six categories of foundations. Nearly half of community foundation grants $(39.6 \%)$ were given to reconstructive surgery (\$992 730). The remainder was split among all other specialties. Ophthalmology ( $\$ 6$ million) and cleft surgery (\$5.6 million) each received more than $40 \%$ of the corporate foundation funds with the remainder divided among all specialties. Cleft surgery accounted for $93 \%$ of grants made by uncategorised independent foundations. Similarly, $92 \%$ of all donations by operating foundations were given to ophthalmology organisations. Likewise, reconstructive surgery accounted for $84 \%$ of public charity funds. Obstetric emergency conditions (those requiring urgent surgical care, such as caesarean

Table 5 Total amount of funding from foundations distributed by surgical specialty 2003-2013

\begin{tabular}{lrr}
\hline Surgical specialty & Total funding & $\begin{array}{c}\text { Percentage } \\
\text { of total }\end{array}$ \\
\hline Ophthalmology & $\$ 40932280.64$ & 38.70 \\
Cleft & $\$ 34052712.59$ & 32.20 \\
Obstetric emergency & $\$ 12815112.89$ & 12.12 \\
Reconstructive & $\$ 7461168.91$ & 7.05 \\
Obstetric fistula & $\$ 5535578.79$ & 5.23 \\
Cardiac & $\$ 1546149.91$ & 1.46 \\
Orthopaedic & $\$ 1134262.60$ & 1.07 \\
Burn & $\$ 854992.59$ & 0.81 \\
Other & $\$ 522695.56$ & 0.49 \\
General & $\$ 330933.61$ & 0.31 \\
Mix & $\$ 234182.96$ & 0.22 \\
Anaesthesia & $\$ 208676.39$ & 0.20 \\
Paediatric & $\$ 117121.43$ & 0.11 \\
Neurosurgery & $\$ 23527.52$ & 0.02 \\
All & $\$ 105769396.40$ & 100.00 \\
\hline
\end{tabular}

section) were exclusively funded by independent foundations.

Table 5 shows the total amount of funding received by different specialties. The 'other' category includes neurosurgery, urology, anaesthesia, mixed specialty surgical teams and unspecified specialty. Cleft surgery (\$34 million) and ophthalmology (\$40.9 million) account for $70 \%$ of the total donated funds.

Surgical delivery ( $\$ 35$ million) and unspecified donations ( $\$ 26.1$ million) account for nearly $60 \%$ of all funds given. Infrastructure (\$1.7 million) encompasses equipment, supplies and surgical centre/operating room establishment. Surgical training (\$7.1 million) refers to training local surgical providers.

Research (\$14.6 million) includes funds for evaluating surgical conditions and postoperative outcomes. Notably, $\$ 11$ million of the $\$ 14.6$ is a single grant on postoperative outcomes of trichiasis surgery in Africa. Other items in this category include conferences. Low cost technology and innovation (\$13.2 million) include developing tools to reduce or prevent fatal postpartum haemorrhage, producing a pulse oximetry probe for mothers undergoing caesarean section and creating low cost orthopaedic prosthesis. Advocacy (\$42 223) refers to patient outreach, in this case for women suffering from obstetric fistulas.

Operations management ( $\$ 8$ million) is the operational costs of running an organisation, including the costs associated with fundraising.

\section{US Agency for International Development}

Six projects (executed between 2006 and 2013) were identified as related to surgical conditions, all concerning obstetric fistulas. With the exception of Bangladesh, all projects were in Sub-Saharan Africa. The total funds allocated were $\$ 438$ million. 


\section{National Institutes of Health}

Twenty-two different research projects were funded between 1991 and 2014, totalling \$31.3 million. Only four projects were not related to trauma (3 general surgery and 1 ophthalmology). Despite trauma accounting for nearly $80 \%$ of projects, it only accounted for $50 \%$ of total funds awarded. General surgery comprised $12 \%$ of projects but amassed nearly one-third of funding (31.6\%). Ophthalmology, the most funded specialty in the private sector, only accounted for $18.4 \%$ of NIH funding.

Africa (30.5\%) and Latin America (32\%) account for nearly two-thirds of these funded projects. The remaining one-third is devoted to the regions of Eastern Europe $(10.9 \%)$, the Middle East $(8.6 \%)$, Southeast Asia $(8.6 \%)$ and global (unspecified region, $9.4 \%$ ). Two projects comprised this global region. One was the development of a low cost negative pressure wound therapy system for LMICs. The second was the many years of the National Eye Institute's (NEI) contribution to the WHO's Prevention of Blindness programme. Although the Fogarty International Center was the main grant administrator and funder, six other institutes and offices also made significant contributions-the Office of the Director, National Eye Institute, National Heart Lung and Blood Institute, National Institute of Alcohol Abuse and Alcoholism, National Institute of Biomedical Engineering and Bioimaging and the National Institute of Child Health and Human Development.

\section{DISCUSSION}

The aim of this study was to describe funding flows to global surgery via private charitable and public channels from the USA. We found that while detailed information regarding funding flows to surgical care is limited, two patterns emerged from the available data. First, the private charitable sector contributed significantly more funds than did the government sector. Second, there are clear donor preferences for surgical specialties and services.

The US non-profit private sector is an important funder of global surgery-thus it is a powerful stakeholder to be engaged in advocacy for greater funding towards global surgery. From the foundation perspective, those classified as family/individual foundations account for nearly three-quarters of total funds donated, while corporate foundations support an eighth of funds. This skewed distribution, in which family and individual foundations are dominant, may explain why certain surgical specialties receive the most funding - these foundations are not publicly accountable, but are governed by individuals or families who are free to decide their priorities. A key guiding principle of the Bill and Melinda Gates Foundation, for example, is that it is "driven by the interests and passions of the Gates family". ${ }^{25}$ Our study found that together, ophthalmology and cleft surgery account for nearly three-fourths of funding among surgical specialties. Moreover, elective surgery is favoured over emergency care. Surgical delivery and operations management were the top two specified reasons for fund allocation. In contrast, local capacity building, such as infrastructure and surgical training, was among the least funded areas of surgery. Notably, a significant portion of funds was also unspecified. It is not possible to determine where these funds were spent, but it is possible some may have been used for capacity building.

A similar pattern exists with US charitable organisations, which account for the largest funding stream for global surgery. Disbursements from these organisations also favour elective procedures and surgical care delivery. Most frequently, these services are provided through short-term, narrowly focused interventions. There is less assistance given to emergency surgical care and training local staff. Ophthalmology accounts for over half of the funding from US charitable organisations $(54 \%)$, while cleft/lip palate (23\%) and mixed services $(12 \%)$ make up the next biggest proportion. Every other specialty receives less than $3 \%$ of total charitable organisation funding.

Funding for surgical care in LMICs among US foundations and charitable organisations appears poorly aligned with the burden of surgical conditions in LMICs, focusing mainly on vertical programmes in ophthalmology and cleft care. Educating donors and charitable organisations about the most pressing global surgery needs and emphasising comprehensive sustainable care may facilitate closer alignment of funding with local needs.

Likewise, USAID appears to be focused on obstetric fistula work and the NIH is heavily skewed towards trauma. Both contribute very small proportions of their budgets to surgical conditions in LMIC.

There are several study limitations. First, though the US provides global health funding via other avenues like UN agencies and PEPFAR, the proportion of that funding for surgery could not be determined. Therefore, these channels were excluded. Similarly, some broad NIH grants like the Medical Education Partnership Initiative (MEPI) and the Fogarty Training grants were excluded due to inability to ascertain exact proportions spent on surgical education and training. Additionally, USAID supports projects focusing on health system strengthening (HSS) and health workforce issues. The exact quantities of these project funds that specifically go towards surgery could not be determined, so they were omitted. However, in 2014, only 3\% ( $\$ 250$ million) of all USAID DAH was for HSS and very little of that was targeted at strengthening surgical services. ${ }^{26}$

One potentially useful future strategy to try estimating funding flows to surgery would be the application of a modified form of the 'Muskoka methodology'. ${ }^{27}$ In trying to assess how much funding goes to women's and children's health (WCH), the same challenge occurred in that these funds were not precisely tracked, although it was clear that plenty of funding given to other tracked 
areas were directly benefiting WCH. The Muskoka methodology was developed in response. It imputes the proportion of categorised funding that directly benefits WCH by (1) directly asking multilateral organisations to estimate percentage of funds benefiting WCH and (2) for bilateral aid, using existing demographics and its relation to disease burden and mortality. The latter approach may still pose some challenges, as not all the existing linkages necessary for the imputations are available for surgery as they are for WCH.

A second limitation is that the foundation data are limited to only the organisations listed in FCOD. Any foundation that funds global surgery not listed were not included in these results. The timeframe is also limited due to data availability (begins in 2003 and finishes with a few documented funds for 2013).

Third, the US charitable organisations' data only includes those that provided exclusively surgical care and no other service. There are many other charitable organisations (eg, Partners in Health) that in some countries provide a significant amount of surgical services in addition to other forms of medical care and developmental aid. However, their financial documents do not indicate the portion of their funds allocated to surgery as opposed to other activities, thus they were excluded. Nonetheless, it is important to acknowledge that many such organisations exist and provide invaluable efforts to advancing global surgery. Furthermore, we excluded organisations for which financial data were not available. Perhaps such organisations were not officially registered as charitable entities and thus were not required to provide forms 990. Likewise, only funds accounted for on the federal tax form 990 are tracked and included in this study. Any additional funds received but not included on the 990 are not accounted for.

Fourth, in order to obtain aggregate funds across channels, it is vital to address double counting. However, in this paper we do not aggregate across channels, thus we did not adjust for double counting. Owing to the nature of our data the main areas vulnerable to double counting would be funds that foundations contributed to charitable organisation. Specifically, we know that some of the funds accounted for in the $\$ 105$ million contribution from foundations are also included in charitable organisations' revenues of $\$ 2.67$ billion.

Lastly, there are inherent limitations related to keyword searches, particularly in the absence of a standardised means for classifying and describing surgical care. It is possible that funds allocated to global surgery were not picked up with the keywords employed in our search.

It is beyond the scope of this research to determine precisely how much DAH should target surgical care. Since the cost-effectiveness, cultural appropriateness and availability of interventions vary across different contexts it does not follow that funding should not perfectly match disease burden. Still, cost-effective surgical interventions seem to be receiving strikingly little attention from donors.
Our study has two conclusions. First, as evidenced by the limited data sources, better tracking of all external financing sources in global health is required, including disaggregation of expenditure within budgets. This tracking is not aimed at encouraging vertical programming and funding, but is required for quantification of funding gaps for clinical services such as surgery; to ensure that resources materialise from promises; and to encourage accountability and transparency. Second, we have shown that within the data limitations, US funding does not wholly align with what is currently understood about surgical need in LMICs. Specifically, we found that most funding is targeted towards elective and often specialised procedures and provision of clinical services, often by foreign teams, rather than emergency and basic surgery along with local capacity building.

\section{Author affiliations}

${ }^{1}$ Department of Surgery, Montefiore Medical Center, Bronx, New York, USA

${ }^{2}$ Center for Surgery and Public Health, Brigham and Women's Hospital,

Boston, Massachusetts, USA

${ }^{3}$ UNC Project Malawi, Lilongwe, Malawi

${ }^{4}$ Institute of Health Metrics and Evaluation, University of Washington, Seattle, Washington, USA

${ }^{5}$ Department of Global Health, King's Centre for Global Health, King's Health Partners \& King's College London, London, UK

${ }^{6}$ Program in Global Surgery and Social Change, Harvard Medical School, Boston, Massachusetts, USA

${ }^{7}$ Boston Children's Hospital, Boston, Massachusetts, USA

${ }^{8}$ Duke Global Health Institute, Duke University, Durham NC, USA

${ }^{9}$ Office of Global Surgery, Massachusetts Eye and Ear Infirmary, Boston, Massachusetts, USA

${ }^{10}$ Department of Otology and Laryngology, Harvard Medical School, Boston, Massachusetts, USA

Correction notice This article has been corrected since it was published online. The institutions that Mark Shrime and Gavin Yamey are affiliated with have been corrected.

Twitter Follow Lily Gutnik at @Igutnik

Contributors LG, MGS, AJD, JGM all contributed to the design of the study. LG did the data collection and analysis. All authors contributed to data interpretation. All authors contributed to writing and editing the manuscript. All authors have seen and approved the final version of the manuscript for publication.

Funding This research received no specific grant from any funding agency in the public, commercial or not-for-profit sectors.

Competing interests None declared.

Provenance and peer review Not commissioned; externally peer reviewed.

Data sharing statement Data set is available by emailing the corresponding author Lily.gutnik@mail.harvard.edu.

Open Access This is an Open Access article distributed in accordance with the Creative Commons Attribution Non Commercial (CC BY-NC 4.0) license, which permits others to distribute, remix, adapt, build upon this work noncommercially, and license their derivative works on different terms, provided the original work is properly cited and the use is non-commercial. See: http:// creativecommons.org/licenses/by-nc/4.0/

\section{REFERENCES}

1. Shrime MG, Sleemi A, Ravilla TD. Charitable platforms in global surgery: a systematic review of their effectiveness, cost-effectiveness, sustainability, and role training. World J Surg 2015;39:10-20. 
2. Debas HGR, McCord C, Thind A. Surgery. 2nd edn. New York: Oxford University Press, 2006

3. Shrime MG, Bickler SW, Alkire BC, et al. Global burden of surgical disease: an estimation from the provider perspective. Lancet Global Health 2015;3(Suppl 2):S8-9.

4. Bickler SW, Weiser TG, Kassebaum N, et al. The Global burden of surgical conditions. Disease Control Priorities, 3rd ed, 2015:19.

5. Meara JG, Leather AJ, Hagander L, et al. Global Surgery 2030: evidence and solutions for achieving health, welfare, and economic development. Surgery 2015;158:3-6.

6. Citron I, Chokotho L, Lavy C. Prioritisation of surgery in the National Health Strategic Plans of Africa: a systematic review. Lancet 2015;385(Suppl 2):S53.

7. Choo S, Perry $\mathrm{H}$, Hesse AA, et al. Assessment of capacity for surgery, obstetrics and anaesthesia in 17 Ghanaian hospitals using a WHO assessment tool. Trop Med Int Health 2010;15:1109-15.

8. Knowlton LM, Chackungal S, Dahn B, et al. Liberian surgical and anesthesia infrastructure: a survey of county hospitals. World J Surg 2013;37:721-9.

9. Linden AF, Sekidde FS, Galukande M, et al. Challenges of surgery in developing countries: a survey of surgical and anesthesia capacity in Uganda's public hospitals. World J Surg 2012;36:1056-65.

10. Notrica MR, Evans FM, Knowlton LM, et al. Rwandan surgical and anesthesia infrastructure: a survey of district hospitals. World J Surg 2011;35:1770-80.

11. Chao TE, Sharma K, Mandigo M, et al. Cost-effectiveness of surgery and its policy implications for global health: a systematic review and analysis. Lancet Glob Health 2014;2:e334-45.

12. Grimes CE, Henry JA, Maraka J, et al. Cost-effectiveness of surgery in low- and middle-income countries: a systematic review. World $\mathrm{J}$ Surg 2014;38:252-63.

13. Dieleman JL, Graves CM, Templin T, et al. Global health development assistance remained steady in 2013 but did not align with recipients' disease burden. Health Affairs 2014;33:878-86.

14. Cometto G, Ooms G, Starrs A, et al. A global fund for the health MDGs? Lancet 2009;373:1500-2.
15. Kates J, Morrison JS, Lief E. Global health funding: a glass half full? Lancet 2006;368:187-8.

16. Piva P, Dodd R. Where did all the aid go? An in-depth analysis of increased health aid flows over the past 10 years. Bull World Health Organ 2009;87:930-9.

17. Ravishankar N, Gubbins P, Cooley RJ, et al. Financing of global health: tracking development assistance for health from 1990 to 2007. Lancet 2009;373:2113-24.

18. USAID. Where does the money go? Secondary where does the money go? http://www.usaid.gov/results-and-data/budget-spending/ where-does-money-go

19. NIH Budget 2013. Secondary NIH Budget 2013. http:// officeofbudget.od.nih.gov/pdfs/FY13/FY 2013 Full-Year CR Operating Plan Posting.pdf

20. Casey KM. The global impact of surgical volunteerism. Surg Clin North Am 2007;87:949-60.

21. Bolkan HA, Samai MM, Bash-Taqi DA, et al. Met and unmet needs for surgery in Sierra Leone: a comprehensive, retrospective, countrywide survey from all health care facilities performing surgeries in 2012. Surgery 2015;157:992-1001.

22. Key Facts on US Foundations: Foundation Center. 2013:7. http:// foundationcenter.org/gainknowledge/research/keyfacts2014/

23. What is a foundation. Secondary what is a foundation. http:// grantspace.org/tools/Knowledge-Base/Funding-Resources/ Foundations/what-is-a-foundation

24. About USAID. Secondary about USAID. http://www.usaid.gov/ what-we-do/global-health.

25. [No authors listed]. What has the Gates Foundation done for global health? Lancet 2009;373:1577.

26. IHME Developmental Assistance for Health 2014 database. 2014. http://ghdx.healthdata.org/record/development-assistance-healthdatabase-1990-2011

27. Methodology for Calculating Baselines and Commitments: G8 Member Spending on Maternal, Newborn and Child Health. Secondary Methodology for Calculating Baselines and Commitments: G8 Member Spending on Maternal, Newborn and Child Health. 2010. http://www.g8.utoronto.ca/summit/2010muskoka/ methodology.html 


\section{Correction}

Gutnik L, Dieleman J, Dare AJ, et al. Funding allocation to surgery in low and middle-income countries: a retrospective analysis of contributions from the USA. BMJ Open 2015;5:e008780.

Mark G Shrime should be attributed to affiliation 8 - Office of Global Surgery, Massachusetts Eye and Ear Infirmary, Boston, Massachusetts, USA and affiliation 10 - Department of Otology and Laryngology, Harvard Medical School, Boston, Massachusetts, USA. Gavin Yamey should be attributed to affiliation 9 - Duke Global Health Institute, Duke University, Durham NC, USA.

BMJ Open 2015;5:e008780. doi:10.1136/bmjopen-2015-008780corr1

CrossMark 